\title{
Immunotherapy in head and neck cancer: A review
}

\author{
Shaik Ali Hassan ${ }^{1}$, Sumit Bhateja ${ }^{2 *}$, Geetika Arora ${ }^{3}$ \\ ${ }^{1}$ Dental Surgeon, ${ }^{2} \mathrm{HOD},{ }^{3}$ Reader, ${ }^{\mathbf{1}, 2}$ Dept. of Oral Medicine and Radiology, ${ }^{\mathbf{3}}$ Dept. of Public Health Dentistry, ${ }^{\mathbf{1}, 2}$ Manav Rachna Dental \\ College, Faridabad, Haryana, ${ }^{3}$ Inderprastha Dental College, Ghaziabad, Uttar Pradesh, India \\ *Corresponding Author: Sumit Bhateja \\ Email: bhateja.sumit@gmail.com
}

\begin{abstract}
Immunotherapy is one of the newer entities which is promising, at least can be very much helpful as an adjuvant therapy. This newer modality of the treatment in the field of cancer treatment may be the fourth pillar supporting surgery, chemotherapy, and radiotherapy. Careful selection of patient is the key for success of immunotherapy, which is based on patient's immunological contexture. In this article we will try to give idea about the immunotherapy in treatment of head and neck cancer and it is a ongoing research.
\end{abstract}

Keywords: Immunotherapy, Natural killer cells, Human papiloma virus, Chemotherapy.

\section{Introduction}

Head-and-neck squamous cell malignant growths are one of the most well-known tumours worldwide and represent the greater part million new cases and 480,000 passing for each year. ${ }^{1}$ Major etiological hazard factor incorporates tobacco use, betel-quid and areca-nut biting, liquor utilization, human papillomavirus (HPV) contamination (oropharyngeal disease), and Epstein-Barr infection disease (nasopharyngeal cancer). ${ }^{2}$ An enormous number of patients are determined to have privately propelled ailment and require multimodal treatment approaches. ${ }^{3}$ Despite progresses in radiation and careful procedures and the utilization of chemotherapy and monoclonal antibodies in cutting edge ailment, the greater part of all patients repeat remotely.

Tumor cells from different strong malignancies, including HNSCC, over-express PD-LI to habituate the safe checkpoint pathways to sidestep insusceptible surveillance. ${ }^{4}$ Pembrolizumab and nivolumab are PD-1 antibodies that intrude on the immunosuppressive pathway of inhibitory checkpoints, which are utilized by tumor cells to anticipate the carcinoma.

\section{Mechanism Responsible for Carcinogenesis Immune evasion}

Maintaining a strategic distance from insusceptible devastation is one of the signs of cancer. ${ }^{5}$ Tumors sidestep invulnerable reaction through various immunologic opposition systems: advancement of T-cell resistance, tweak of fiery and angiogenic cytokines, downregulation of antigen processing machinery (APM), and the outflow of safe checkpoint ligand end receptors. ${ }^{6}$ Tumor cells additionally build up a safe suppressive microenvironment by advancing the emission of immunosuppressive cytokines, for example, tumor growth factor-beta (TGF $\beta$ ) and interleukin 10 (IL-10) which smother T-cell multiplication and cytotoxic capacity and downregulate articulation of co-stimulatory particles and MHC. ${ }^{7}$ These cytokines repress dendritic cell development, macrophage enactment, cytolysis by normal killer cells, and Cytotoxic $\mathrm{T}$ lymphocytes. There are three kinds of immunosuppressive hematopoietic cells that are selected in the tumor microenvironment and assume a significant job in insusceptible getaway: myeloid-inferred silencer cells (MDSCs), tumor-related macrophages (TAMs), and administrative T-cells (Tregs). Penetrating MDSCs produce arginase-I to utilize L-arginine (which is a basic amino corrosive that is critical for the capacity of T-cells) to hose Tcell response. ${ }^{8-10}$

HPV malignant growth is a key model for understanding tumor safe evasion. ${ }^{11}$ Although HPV disease is normal, HPVrelated malignancy is very rare. ${ }^{12}$ Various investigations have demonstrated that HPV-contaminated cells effectively advance stromal irritation and collaborate with nearby microenvironment to advance oncogenesis. ${ }^{13}$ In HPV-related malignancy, there is a feeble T-cell reaction to HPV early antigens in blood alongside elevated levels of TILs that need cytotoxicity and expanded quantities of IL-10 creating Tregs. ${ }^{14} \mathrm{HPV}+$ Head-and-neck squamous cell cancers additionally has significant levels of T-invaded lymphocytes with high PD-1 articulation, and significant levels of PD-L1 articulation on tumor cells, and TAMs. ${ }^{15}$ These outcomes mean that a characteristic immunologic reaction is produced against HPV Head-and-neck squamous cell cancers which incite PD-1/PD-L1 pivot and may confine the limit of TILs to come full circle an immunologic assault.

\section{Immune tolerance}

Immune toerance is characterized as inability to mount a resistant reaction to antigen. Tumor cells are heterogeneous with nonuniform articulation of tumor-related antigens and tumor-explicit antigens (TSAs). ${ }^{16}$ Head and neck cancer cells with elevated levels of tumor-explicit antigens are bound to be recognized by the safe framework and wiped out when contrasted with Head-and-neck squamous cell cancers cells with no or low degrees of tumor-explicit antigens which display low immunogenicity and break from resistant surveillance. ${ }^{17,18}$ The interchange between tumor antigen and TA-explicit is important for Cytotoxic $\mathrm{T}$ lymphocytes acknowledgment and tumor cell pulverization. antigen processing machinery segments work pair to produce antigenic peptides, translocate into endoplasmic reticulum, load MHC Class I H chain with peptides, lastly transport MHC Class I particles to the cell surface to display the 
peptide to T-lymphocytes. ${ }^{19}$ Tumor cells can possibly diminish $\mathrm{T}$ cell-interceded acknowledgment by downregulating or changing HLA I atoms or potentially antigen processing machinery segments to constrict antigen introduction.

\section{Disruption of $\mathbf{T}$ cell regulation}

$\mathrm{T}$ cell receptors associate with co-invigorating ligands and co-stimulatory receptors to give $\mathrm{T}$-cell signal acknowledgment. Malignant growth cells repress T-cellinterceded acknowledgment and initiation by downregulating MHC I antigen introduction to endogenous $\mathrm{T}$ cell receptors and furthermore through the inhibitory co-stimulatory receptor pathways. ${ }^{20}$ Two of the most usually included checkpoint inhibitory components are CTLA-4 and PD1/PD-L1, which act at prior and later phases of insusceptible reaction to tumors. CTLA- 4 rivals CD28 receptor, an initiating co-stimulatory receptor, for authoritative to B7 ligand (CD80 and CD86) found on APCs, bringing about Tcell inactivation. In ordinary cells, PD-1 ties to its ligands PD-L1/PD-L2 to lessen T-cell effector movement and end invulnerable reaction. In any case, PD-L1 is overexpressed in most of tumors, and this resistant brake signal is embraced by cells to avoid invulnerable elimination.

\section{Different types of Immunotherapy in Head and Neck Cancer}

\section{Checkpoint Inhibitor}

Allison made a major leap forward in the field of invulnerable oncology by setting up another idea that, aside from antigen introduction, enactment of cytotoxic $\mathrm{T}$ cells required an optional costimulatory sign to accomplish antitumor invulnerability. The revelation of inhibitory pathways, which stifle T-cell movement prompting tumor development, made a major transformation in the field of immunotherapy. Obstructing these inhibitory pathways by means of monoclonal antibodies, which are generally called checkpoint inhibitors, has demonstrated to be probably the most ideal approaches to relapse tumor. ${ }^{21-23}$

Checkpoint hindrance has an assortment of utilizations in resistant oncology running from lung malignant growth to oral cancer. ${ }^{24-27}$ Among checkpoint inhibitors, hostile to CTLA-4 and against PD-1 antibodies are generally utilized for helpful purposes. Hostile to CTLA-4 antibodies have more extensive $\mathrm{T}$ cell work contrasted with against PD-1 antibodies, which reestablishes that enemy of CTLA-4 has more reactions than hostile to PD-1. As of late, against PDL1 ligand is in the late period of business improvement for clinical practice with name durvalumab. Ipilimumab was endorsed by the European Organization for Research and Treatment of Cancer (EORTC) for the adjuvant treatment in patients with high-chance melanoma. ${ }^{28}$ The blend of nivolumab and ipilimumab was affirmed in the United States for the treatment of BRAF-negative melanoma. Apart from hostile to PD-1 and against CTLA-4 antibodies, other checkpoint inhibitor receptors, for example, lymphocyteactivation gene 3 (LAG3), mucin domain3 (TIM-3), and T- cell immunoglobulin have shown restorative impacts in clinical preliminaries in mix with PD-1 agents. ${ }^{29.30}$ The mix of radiation and PD-1 barricade was demonstrated to be synergistic in the treatment of cancer. ${ }^{31}$

\section{Targeted monoclonal bodies}

Monoclonal antibodies are produced using either human or murine neutralizer parts that bound to tumor-related antigen prompting ADCC. The best model in this gathering which is utilized remedially is counter acting agent against epidermal growth factor. Deregulation of epidermal growth factor prompts the restraint of apoptosis, intrusion, metastasis, and angiogenic potential. ${ }^{32,33}$ Compared to typical mucosa, epidermal growth factor level is expanded in $95 \%$ of Headand-neck squamous cell cancers. ${ }^{34}$ In Head-and-neck squamous cell cancers, the statement of epidermal growth factor is expanded, which corresponds with hostility of the malignancy. EGFR is answerable for tumor movement in numerous strong tumors, particularly in Head-and-neck squamous cell cancers. ${ }^{35}$ Monoclonal antibodies, for example, cetuximab and panitumumab are epidermal growth factor focused on treatments; they are demonstrated to be successful against either alone or in blend with radiotherapy. ${ }^{36}$

\section{Adoptive immunisation}

The significance of $\mathrm{T}$ cells in the end of malignant growth cells is a settled marvel. Lymphocytes from tumor test or blood of the patient are collected, extended, and reintroduced for antitumor immunity. ${ }^{37,38}$ The viability of $\mathrm{T}$ cells can be emphasizd by bringing explicit antigen receptor into the cells by hereditary building, consequently upgrading their capacity to perceive tumor antigen. ${ }^{39}$ Encouraging outcomes were found in 93 patients treated for metastatic melanoma utilizing adoptive cell transfer. This procedure has demonstrated excellent to treat metastatic strong tumors, which are generally hard to treat with customary strategies. Adoptive cell transfer with human papillomavirus - directed tumorpenetrating $\mathrm{T}$ cells has indicated promising outcomes in patients with cervical cancer. ${ }^{40}$ Improvements in adoptive cell transfer are picking up force as a result of its prosperity rate; presentation of explicit antigen receptor into $\mathrm{T}$ cells will slaughter disease cells specifically. Large-scale generation for clinical utilization of adoptive cell transfer is endeavored by building antigen receptors: one strategy is through complemented introduction of significant histocompatibility complex and the other is through chimeric antigen receptor.

\section{Cytokine immunotherapy}

Cytokines are sub-atomic delivery system that permit the cells of our resistant framework to speak with one another to create an organized reaction to an objective antigen (disease cell). This immunotherapy animates insusceptible cells through a convoluted pathway, in this way expanding coordination between tumor cells and stromal cells. As of late, various cytokines have been created for the treatment of malignant growth. Two cytokines as of now affirmed by the 
FDA for clinical reasons for existing are interferon $\alpha$ (IFN $\alpha)$ and interleukin 2 (IL-2).

\section{IFN $\alpha$}

These cytokines when infused subcutaneously in renal cell carcinoma have demonstrated tumor relapse. These have demonstrated magnificent outcomes in organize 3 melanoma. The blend of IFN $\alpha$ and IL-2 indicated fractional reaction and higher toxicity. ${ }^{41}$

IL-2- It is a FDA-endorsed cytokine for metastatic melanoma. These cytokines increment level of Natural Killer cells and tumor-infiltrating lymphocytes (TILs) in the lesion. ${ }^{42,43}$ Perilymphatic IL-2 organization has expanded the endurance pace of patients with Head-and-neck squamous cell cancers ${ }^{44}$ expanded tumor receptive $\mathrm{T}$ cells were found in patients who experienced monoclonal counter acting agent treatment after surgery. ${ }^{45}$

\section{Conclusion}

Cancer treatment is one of the difficult perspectives in the treatment modalities extending from medical procedure to chemotherapy and radiation are yielding blended outcomes. To defeat this obstacle, more up to date imaginative methodologies are expected to lessen the dreariness and mortality of the patients. The weaknesses of medical procedure, for example, repeat of tumor or non-resectable injury and poisonous quality of radiotherapy or chemotherapy can be significantly diminished by immunotherapy when utilized in blend with these treatment modalities. Principle issues with immunotherapy is the absence of strong prescient markers of viability, particularly when the expenses of these medications are considered. It is still ongoing test for the treatment of head and neck cancer.

\section{Source of Funding}

None.

\section{Conflict of Interest}

None.

\section{References}

1. Fitzmaurice C, Allen C, Barber RM, Barregard L, Bhutta ZA. Global burden of disease cancer collaboration. Global, regional, and national cancer incidence, mortality, years of life lost, years lived with disability, and disability-adjusted lifeyears for 32 cancer groups, 1990 to 2015: A systematic analysis for the global burden of disease study. JAMA Oncol. 2017;3:524-48.

2. Sankaranarayanan R, Masuyer E, Swaminathan R, Ferlay J, Whelan S. Head and neck cancer: A global perspective on epidemiology and prognosis. Anticancer Res. 1998;18:477986.

3. Sankaranarayanan R, Ramadas K, Thomas G, Muwonge R, Thara S, Mathew B, et al. Effect of screening on oral cancer mortality in Kerala, India: A cluster-randomised controlled trial. Lancet. 2005;365:1927-33.

4. He J, Hu Y, Hu M, Li B. Development of PD-1/PD-L1 pathway in tumor immune microenvironment and treatment for non-small cell lung cancer. Sci Rep. 2015;5:13110.

5. Hanahan D, Weinberg RA. Hallmarks of cancer: The next generation. Cell. 2011;144:646-74.
6. Pitt JM, Vétizou M, Daillère R, Roberti MP, Yamazaki T, Routy B, et al. Resistance mechanisms to immune-checkpoint blockade in cancer: Tumor-intrinsic and -extrinsic factors. Immun. 2016;44:1255-69.

7. Nagaraj S, Schrum AG, Cho HI, Celis E, Gabrilovich DI. Mechanism of $\mathrm{T}$ cell tolerance induced by myeloid-derived suppressor cells. J Immunol. 2010;184:3106-16.

8. Vasquez-Dunddel D, Pan F, Zeng Q, Gorbounov M, Albesiano $\mathrm{E}, \mathrm{Fu}$ J, et al. STAT3 regulates arginase-I in myeloid-derived suppressor cells from cancer patients. J Clin Invest. 2013;123:1580-9.

9. Califano JA, Khan Z, Noonan KA, Rudraraju L, Zhang Z, Wang $\mathrm{H}$, et al. Tadalafil augments tumor specific immunity in patients with head and neck squamous cell carcinoma. Clin Cancer Res. 2015;21:30-8.

10. Young MR, Wright MA, Lozano Y, Prechel MM, Benefield J, Leonetti JP, et al. Increased recurrence and metastasis in patients whose primary head and neck squamous cell carcinomas secreted granulocyte-macrophage colonystimulating factor and contained CD34+ natural suppressor cells. Int J Cancer. 1997;74:69-74.

11. Westrich JA, Warren CJ, Pyeon D. Evasion of host immune defenses by human papillomavirus. Virus Res. 2017;231:2133.

12. Bansal A, Singh MP, Rai B. Human papillomavirus-associated cancers: A growing global problem. Int J Appl Basic Med Res. 2016:6:84-9.

13. Woodby B, Scott M, Bodily J. The interaction between human papillomaviruses and the stromal microenvironment. Prog Mol Biol Transl Sci. 2016;144:169-238.

14. Smola S, Trimble C, Stern PL. Human papillomavirus-driven immune deviation: Challenge and novel opportunity for immunotherapy. Ther Adv Vaccines. 2017;5:69-82.

15. Ono T, Azuma K, Kawahara A, Sasada T, Hattori S, Sato F, et al. Association between PD-L1 expression combined with tumor-infiltrating lymphocytes and the prognosis of patients with advanced hypopharyngeal squamous cell carcinoma. Oncotarget. 2017;8:92699-714.

16. Mroz EA, Tward AD, Hammon RJ, Ren Y, Rocco JW. Intratumor genetic heterogeneity and mortality in head and neck cancer: Analysis of data from the cancer genome atlas. PLoS Med. 2015;12:e1001786

17. Dunn GP, Bruce AT, Ikeda H, Old LJ, Schreiber RD. Cancer immunoediting: From immunosurveillance to tumor escape. Nat Immunol. 2002;3:991-8.

18. Khong HT, Restifo NP. Natural selection of tumor variants in the generation of "tumor escape" phenotypes. Nat Immunol. 2002;3:999-1005.

19. Ferris RL, Whiteside TL, Ferrone S. Immune escape associated with functional defects in antigen-processing machinery in head and neck cancer. Clin Cancer Res. 2006;12:3890-5.

20. López-Albaitero A, Nayak JV, Ogino T, Machandia A, Gooding W, DeLeo AB, et al. Role of antigen-processing machinery in the in vitro resistance of squamous cell carcinoma of the head and neck cells to recognition by CTL. $J$ Immunol. 2006;176:3402-9.

21. Harding FA, McArthur JG, Gross JA, Raulet DH, Allison JP. CD28-mediated signalling co-stimulates murine $\mathrm{T}$ cells and prevents induction of anergy in T-cell clones. Nat. 1992;356:607-9.

22. Tivol EA, Borriello F, Schweitzer AN, Lynch WP, Bluestone JA, Sharpe AH. Loss of CTLA-4 leads to massive lymphoproliferation and fatal multiorgan tissue destruction, revealing a critical negative regulatory role of CTLA-4. Immun. 1995;3:541-7.

23. Keir ME, Butte MJ, Freeman GJ, Sharpe AH. PD-1 and its ligands in tolerance and immunity. Annu Rev Immunol. 2008;26:677-704 
24. Brahmer J, Reckamp KL, Baas $\mathrm{P}$, Crinò L, Eberhardt WE, Poddubskaya E, et al. Nivolumab versus docetaxel in advanced squamous-cell non-small-cell lung cancer. $N$ Engl J Med. 2015;373:123-35.

25. Borghaei H, Paz-Ares L, Horn L, Spigel DR, Steins M, Ready $\mathrm{NE}$, et al. Nivolumab versus docetaxel in advanced nonsquamous non-small-cell lung cancer. $N$ Engl J Med. 2015;373:1627-39.

26. Garon EB, Rizvi NA, Hui R, Leighl N, Balmanoukian AS, Eder JP, et al. KEYNOTE-001 Investigators. Pembrolizumab for the treatment of non-small-cell lung cancer. $N$ Engl J Med. 2015;372:2018-28.

27. Hodi FS, O’Day SJ, McDermott DF, Weber RW, Sosman JA, Haanen JB, et al. Improved survival with ipilimumab in patients with metastatic melanoma. $N$ Engl J Med. 2010;363:711-23

28. Keir ME, Butte MJ, Freeman GJ, Sharpe AH. PD-1 and its ligands in tolerance and immunity. Annu Rev Immunol. 2008;26:677-704.

29. Larkin J, Chiarion-Sileni V, Gonzalez R, Grob JJ, Cowey CL, Lao $\mathrm{CD}$, et al. Combined nivolumab and ipilimumab or monotherapy in previously untreated melanoma. $N$ Engl $J$ Med. 2015;373:23-34.

30. Sakuishi K, Apetoh L, Sullivan JM, Blazar BR, Kuchroo VK, Anderson AC. Targeting tim-3 and PD-1 pathways to reverse $\mathrm{T}$ cell exhaustion and restore anti-tumor immunity. $J$ Exp Med. 2010;207:2187-94.

31. Krcik EM. Radiation therapy plus anti-programmed death ligand 1 immunotherapy: A review on overall survival. Radiol Technol. 2016;88:123-8.

32. Normanno N, De Luca A, Bianco C, Strizzi L, Mancino M, Maiello MR, et al. Epidermal growth factor receptor (EGFR) signaling in cancer. Gene. 2006;366:2-16.

33. Grandis JR, Tweardy DJ. Elevated levels of transforming growth factor alpha and epidermal growth factor receptor messenger RNA are early markers of carcinogenesis in head and neck cancer. Cancer Res. 1993;53:3579-84.

34. Salomon DS, Brandt R, Ciardiello F, Normanno N. Epidermal growth factor-related peptides and their receptors in human malignancies. Crit Rev Oncol Hematol. 1995;19:183-232.

35. Vermorken JB, Mesia R, Rivera F, Remenar E, Kawecki A, Rottey S, et al. Platinum-based chemotherapy plus cetuximab in head and neck cancer. $N$ Engl J Med. 2008;359:1116-27.

36. Rabassa ME, Croce MV, Pereyra A, Segal-Eiras A. MUC1 expression and anti-MUC1 serum immune response in head and neck squamous cell carcinoma (HNSCC): A multivariate analysis. BMC Cancer. 2006;6:253.

37. Rosenberg SA, Restifo NP. Adoptive cell transfer as personalized immunotherapy for human cancer. Sci. 2015;348:62-8

38. Sadelain M, Rivière I, Brentjens R. Targeting tumours with genetically enhanced T lymphocytes. Nat Rev Cancer. 2003;3:35-45.

39. Curran KJ, Pegram HJ, Brentjens RJ. Chimeric antigen receptors for T cell immunotherapy: Current understanding and future directions. J Gene Med. 2012;14:405-15.

40. Stevanović S, Draper LM, Langhan MM, Campbell TE, Kwong ML, Wunderlich JR, et al. Complete regression of metastatic cervical cancer after treatment with human papillomavirustargeted tumor-infiltrating T cells. J Clin Oncol. 2015;33:1543-50.

41. Whiteside TL, Letessier E, Hirabayashi H, Vitolo D, Bryant J, Barnes L, et al. Evidence for local and systemic activation of immune cells by peritumoral injections of interleukin 2 in patients with advanced squamous cell carcinoma of the head and neck. Cancer Res. 1993;53:5654-62.

42. Dadian G, Riches PG, Henderson DC, MacLennan K, Lorentzos A, Moore J, et al. Immune changes in peripheral blood resulting from locally directed interleukin-2 therapy in squamous cell carcinoma of the head and neck. Eur J Cancer B Oral Oncol. 1993;29B:29-34.

43. De Stefani A, Forni G, Ragona R, Cavallo G, Bussi M, Usai A, et al. Improved survival with perilymphatic interleukin 2 in patients with resectable squamous cell carcinoma of the oral cavity and oropharynx. Cancer. 2002;95:90-7.

44. Herold-Mende C, Karcher J, Dyckhoff G, Schirrmacher V. Antitumor immunization of head and neck squamous cell carcinoma patients with a virus-modified autologous tumor cell vaccine. Adv Otorhinolaryngol. 2005;62:173-83.

45. Cantoni C, Huergo-Zapico L, Parodi M, Pedrazzi M, Mingari MC, Moretta A, et al. NK cells, tumor cell transition, and tumor progression in solid malignancies: new hints for NKbased immunotherapy? J Immunol Res. 2016;2016:4684268.

How to cite this article: Hassan SA, Bhateja S, Arora G. Immunotherapy in head and neck cancer: A review. J Oral Med, Oral Surg, Oral Pathol, Oral Radiol 2020;6(1):28-31. 